\title{
Changes in sleep EEG with aging in humans and rodents
}

\author{
Diana Campos-Beltrán ${ }^{1,2}$ (D) Lisa Marshall ${ }^{1,2}$ (B) \\ Received: 4 September 2020 / Revised: 17 February 2021 / Accepted: 19 February 2021 / Published online: 1 April 2021 \\ (C) The Author(s) 2021
}

\begin{abstract}
Sleep is one of the most ubiquitous but also complex animal behaviors. It is regulated at the global, systems level scale by circadian and homeostatic processes. Across the 24-h day, distribution of sleep/wake activity differs between species, with global sleep states characterized by defined patterns of brain electric activity and electromyography. Sleep patterns have been most intensely investigated in mammalian species. The present review begins with a brief overview on current understandings on the regulation of sleep, and its interaction with aging. An overview on age-related variations in the sleep states and associated electrophysiology and oscillatory events in humans as well as in the most common laboratory rodents follows. We present findings observed in different studies and meta-analyses, indicating links to putative physiological changes in the aged brain. Concepts requiring a more integrative view on the role of circadian and homeostatic sleep regulatory mechanisms to explain aging in sleep are emerging.
\end{abstract}

Keywords Aging $\cdot$ Sleep $\cdot$ Electrophysiology $\cdot$ EEG $\cdot$ Human $\cdot$ Rodents

Both aging and sleep affect as well as depend upon complex mechanisms involving processes at different structural levels. At the global level, the ventrolateral preoptic nucleus located in the hypothalamus has long been considered the sleep center. However, the existence of wake-sleep regulatory circuits within the hypothalamus, brainstem, and basal forebrain, characterized by functionally specific cell types, has since been disclosed. Findings show that no one nucleus contains only, e.g., sleep-active neurons, but that functionally specific mostly GABA and glutamatergic cell types are co-distributed with varying predominance in different regions or nuclei [46]. The discharge of these cells is regulated by neuromodulators such as acetylcholine, orexin, or norepinephrine, which vary in their action and efficacy. For instance, non-synaptic release of norepinephrine from neurons of the locus coeruleus (LC) enables spatially widespread efficacy, while, at the same time,

This article is part of the special issue on Aging Brain in Pflügers Archiv_-European Journal of Physiology

Lisa Marshall

lisa.marshall@uni-luebeck.de

1 Institute of Experimental and Clinical Pharmacology and Toxicology, University of Lübeck, Ratzeburger Allee 160, 23562 Lübeck, Germany

2 Center for Brain, Behavior and Metabolism, University of Lübeck, Ratzeburger Allee 160, 23562 Lübeck, Germany
LC neuronal activity occurs phase-locked to the sleep slow oscillation [86]. In the case of orexin, activity is key for maintained wakefulness, as indicated by the characteristic wakefulness deficit in narcolepsy when hypothalamic orexinergic activity is impaired [47]. Ascending fibers innervate the neocortex and hippocampus which reflect changes in behavioral state and neuronal activity as well as age-dependent modifications [e.g., 59, 77]. Due to their laminar cytoarchitecture, the neocortex and hippocampus can generate far field potentials, and their electrophysiological signals, especially brain rhythms of the electroencephalogram (EEG), are readily used to assess sleep states in mammals.

In general, large-scale age-related structural changes such as cortical thinning, white matter degeneration, neurotransmitter dysregulation, and/or receptor distribution affect sleep and its electrophysiological representation [27, 78, 120]. Agerelated alterations of many structures and basic physiological mechanisms addressed in this volume likely also affect sleep and sleep/wake processes, e.g., astroglial aging (Verkhratsky \& Semyanov, this volume) and changes in energy metabolism (Lushchak, this volume) as well as in vascular and hemodynamic properties (Robinson, this volume). Furthermore, we refer here to some comprehensive recent reviews on sleepassociated age-related changes in the transcriptome and on epigenetic aging [2, 38, 39, 98].

Sleep is endowed with a multitude of functions, not only neuronal, e.g., memory consolidation or synaptic 
downscaling, but also at immune and metabolic levels [4, 53, $63,99,107]$. In fact, strong evidence suggests that brain rhythms during sleep are more than merely correlates of neuronal activity. In particular, the slow oscillations of non-rapid eye movement sleep (NREMS) are suggested to support immune function [5] and serve waste clearance by reinforcing the glymphatic system function [3]. More recently, studies lend evidence to a restorative function of sleep for the genome, e.g., for DNA break down repair [69].

We aim here to highlight the most robust findings on the impact of aging on sleep in three mammalian species (Fig. 1) as assessed by brain electric activity. The first section gives an overview on the regulation of sleep and the second to fourth on age-related effects on sleep EEG in humans, laboratory mice, and rats respectively.

\section{Regulation of sleep}

How is sleep regulated? The most widely used conceptual model for sleep regulation for the timing and intensity of sleep at the systems level is the Two Process Model by Borbély, first published in 1982 and extensively updated in 2016 [9]. At its core, sleep is regulated by the interaction of a process controlled by the circadian pacemaker $\mathrm{C}$ (Process $\mathrm{C}$ ) and a homeostatic process $\mathrm{S}$ (Process $\mathrm{S}$ ). Thus, effects of aging on functions within either of these two processes may affect sleep. Relevant EEG markers for Process S are slow wave
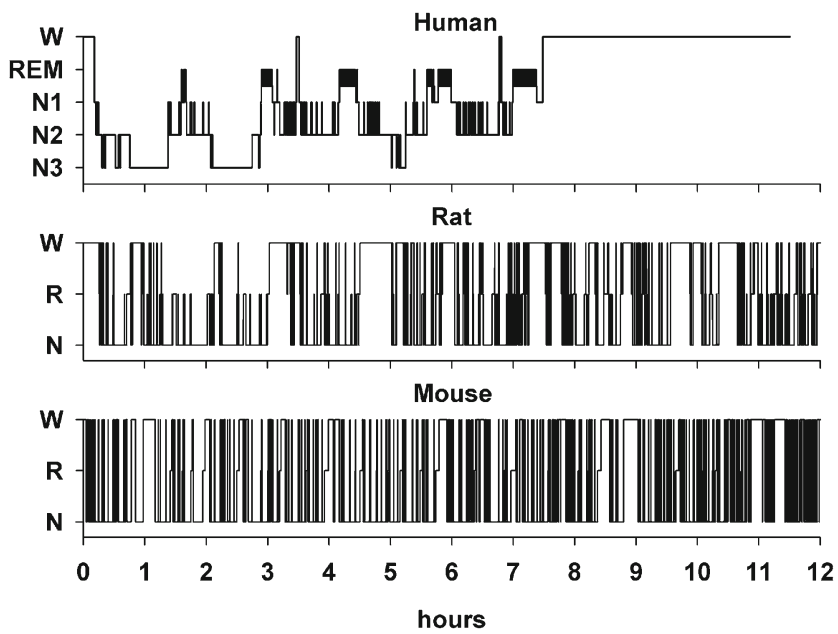

Fig. 1 Comparison of the normal sleep architecture during the inactive sleep period of the three species discussed in this review. Lights out was at $0 \mathrm{~h}$ for the human subject and sleep was recorded during $8 \mathrm{~h}$. The rodent species were held on a 12:12 L:D regime, with lights on depicted at $0 \mathrm{~h}$ and sleep recorded through $12 \mathrm{~h}$. Sleep architecture is determined from EEG and electromyography recordings. Note the typical difference in sleep cycle lengths across species. W wake, REM rapid eye movement sleep, stages N1-N3 in human sleep; W wake, R rapid eye movement sleep, $\mathrm{N}$ non-rapid eye movement sleep in the rodent species. Rat data were kindly provided by Gina R. Poe, University of California, Los Angeles (UCLA) activity (SWA), and theta activity. Both frequency bands reveal regional differentiation, putatively linked to plasticityrelated processes of learning during wakefulness and synaptic homeostasis during sleep $[9,44]$. The homeostatic increases in SWA in response to prolonged prior wakefulness are blunted in older relative to younger subjects in humans $[55,61,70]$ and rodents $[17,51,65,82,101]$. Features of slow waves are discussed below.

The major substance ascribed a homeostatic, centrally mediated function in Process S and expressed in magnitude of EEG slow wave activity is adenosine. Neuronal activity during waking leads via neuro-glial circuitry to a global increment in extracellular adenosine concentrations, with a decrease adenosine occurring during the rest phase $[6,9]$. Aging is suggested to impact homeostatic function in cortical and subcortical regions by modulating production of adenosine, reduced binding sites, binding potential, or efficacy [15, $27,68,71,78]$. Recently, using optogenetic activation, glutamatergic neurons in the basal forebrain were found critically involved in this sleep homeostatic dynamics of adenosine [84]. Mainly protein levels of vesicular glutamate transporter 2 (vGluT2), which transports glutamate into secretory vesicles, reveal age-related changes [94]. Together with the finding that sleep/wake activity drives posttranscriptional processes in forebrain synaptosomes [75], an age-dependent shift in transcriptional vs. posttranscriptional activity may contribute to aging sleep [48].

Which processes are associated to Process C? Melatonin and core body temperature represent the dominant markers of the central pacemaker, the suprachiasmatic nucleus $(\mathrm{SCN})$. The melatonin nocturnal level is strongly reduced from young to middle-aged/elderly $[109,121]$. The circadian core body temperature rhythm is also weakened in aging [111]. Both the circadian phase of melatonin and of core body temperature are reported to move earlier, i.e., phase advance, with age as compared to young adults, yet age-related changes in sleep timing are not attributed to a shortening of circadian period [25]. Common to humans and most rodents, a decrease in amplitude or functional impairment in circadian rhythm is observed, which some studies indicate result from agerelated changes in the molecular machinery of the SCN and non-SCN clocks [18, 23, 73, 114, 119].

A study by Cajochen and colleagues [10] compared agerelated changes in the circadian and homeostatic regulation of sleep between elderly and young adults and concluded that weaker circadian regulation rather than homeostatic regulation underlies age-related changes in sleep. They measured significantly reduced melatonin secretion, reduced circadian modulation of rapid eye movement sleep (REMS), and sleep spindle frequency, but homeostatic responses (measured as SWA response to different levels of sleep deprivation) were only selectively reduced, i.e., over the frontal cortex. This relatively stronger effect of age-related changes in Process $\mathrm{C}$ than in 
Process S is reflected in other studies on circadian-sleep interaction. Sleep in older as compared to younger subjects is much more vulnerable to circadian misalignment [25], which might be due to a reduced sensitivity or responsiveness of the suprachiasmatic nucleus (SCN) to environmental cues and non-image forming functions to light [20,26].

One major hub for the interaction of aging circadian and homeostatic functions is the hypothalamus and related systems $[49,90]$. For instance, melatonin directly inhibits several responses to the adrenocorticotropic hormone (ACTH) in the human adrenal gland, such as cortisol and progesterone production [11]. Cortisol is the peripheral end-point of the neuroendocrine hypothalamic-pituitary-adrenocortical system that interacts reciprocally with the hypothalamic-pituitarysomatotrophic system, thus suggesting convergent agedependent regulators of sleep-related hormone secretion and sleep EEG $[40,105,108]$. Thus, any of the above structures or functions that change over the course of a lifespan can thereby clearly impact sleep. In the original Two Process Model, Processes $\mathrm{C}$ and $\mathrm{S}$ were regulated independently and represented global entities only. Advances at the biochemical and molecular level have deepened our understanding on the complexity of sleep regulatory processes and disclosed common signaling pathways for regulation of the two global processes [52]. Non-SCN circadian clocks in the brain and in the periphery affect sleep $[31,34,66,90]$. Moreover, extra-SCN clock gene expression in the brain, especially in the cortex, is dependent upon prior sleep-wake activity $[9,19]$. In fact, Noya and colleagues revealed that gene expression in synapses is regulated in a circadian fashion while gene translation occurs in response to sleep/wake activity [75].

Furthermore, the concept of an essential contribution of local to global sleep has arisen [52]. Most intensely investigated (local) sleep regulatory substances, i.e., substances that are synthetized or released in an activity-dependent way, and involved in homeostatic regulation are proinflammatory cytokines, such as tumor necrosis factor alpha and interleukin $1 \mathrm{~b}$, or nitric oxide. These substances and/or their signaling cascades reveal age-dependent changes $[29,37,53,54]$.

\section{Age-related effects on sleep EEG in humans}

We define healthy aging human subjects in accordance to a review by Scullin [100] as $\geq 60$ years old, with young and middle-aged defined as $<30$ years and 30-60 years old, respectively. A meta-analyses by Ohayon and colleagues [76] including way over 20 studies used slightly different borders, and included in addition a group of old elderly ( $\geq 70$ years). Of all polysomnographic features, only sleep efficiency, i.e., the ratio of total sleep time (TST) compared to the total time in bed, was lower in this group, attributed most likely to increased sleep fragmentation: From 30 to 60 years of age, wake after sleep onset increased strongly, by about $10 \mathrm{~min}$ per decade, and revealed a strong effect size in the meta-analyses of Ohayon and colleagues. However, after the age of 60 , neither TST, times spent in the different sleep stages, nor wake time after sleep onset changed significantly.

Martin and colleagues reported a moderate increase in sleep latency, i.e., the time required after lights out to reach sleep, with age [64]. Increases seem most apparent within the years after the 30s $[58,76]$. Overall, from young to elderly, the amount of time spent in slow wave sleep (SWS) and REMS decreases, whereas time in lighter NREMS stages N2 and N1 increases [13, 58, 64, 76]. Interestingly, although effects of aging within males and females were generally similar, in the meta-analyses by Ohayon and colleagues [76], larger effect sizes were observed for women in TST, sleep efficiency, and percentage in stage 1 sleep, meaning that age effected these parameters in women more strongly than in men. Women revealed longer TST but also longer sleep latency, than similarly aged men. However, they revealed a greater percentage of SWS as well as less percentage of stage 2 sleep. Despite differences in magnitude in some parameters, the direction of change in both genders was similar. It appears gender differences more than an interaction between gender and age exist [36]. Not considered in this review are the interactions of sleep with menstrual cycle and sex-related circadian variations [8]. A lower percentage of time spent in REMS is frequently reported in middle-aged compared to young subjects, but no further decrease in elderly $[60,62,64]$.

It is to note that not all studies comparing nocturnal sleep in elderly with that of younger adults mention in the methods whether daytime napping occurred. As discussed intensely by $\mathrm{Li}$ et al. [58]. this is no trivial matter, since napping effects Process S. Napping is more frequent in older subjects, yet omission of habitual napping for experimental purposes may bias results, if we are interested in measuring "normal sleep behavior" within a 24-h period. Obviously, permitting habitual naps influences nocturnal sleep drive, and the ability to match parameters of napping such as time of day and duration presents a further challenge. Cognitive performance and physiological (e.g., cardiovascular) functions have been associated positively with napping, thus potentially introducing a further bias when including or excluding habitual nappers [30,67, 74]. In addition to changes in spontaneous sleep, aging may involve a decreased capacity to respond or decreased sensitivity to the accumulation of wakeassociated substances. Several studies report that nocturnal sleep deprivation is associated with less SWS rebound in middle-aged than young adults $[36,93]$.

Information provided from sleep stages and the amplitude or power of EEG brain rhythms is often complimentary. Consistent with reductions in time spent in SWS, spectral power of slow wave activity (SWA, $<4 \mathrm{~Hz}$ ) is reduced in middle-aged and further in older compared to young adults (reviewed in [61]). The slow wave/slow oscillation features 
Fig. 2 Age-related modulations in slow wave activity and sleep spindle density in humans predominate over frontal cortical regions. a Representative head plots of slow wave activity $(<4.6$ $\mathrm{Hz}$, absolute power as measured in $\mu \mathrm{V}^{2}$; left) and density (number of SW/min; right); warmer colors indicate higher values. The middle topoplots reveal the topographical differences in EEG activity between young and older human adults in which the cooler colors indicate greater differences. b Differences in the aged EEG activity in the fast sleep spindle density $(13.5-15 \mathrm{~Hz}$; bottom left) and slow sleep spindle density (12-13.5 Hz; bottom right). Figure taken and modified with permission from Mander and colleagues, Neuron (2017) 94 (1):19-36 [61]

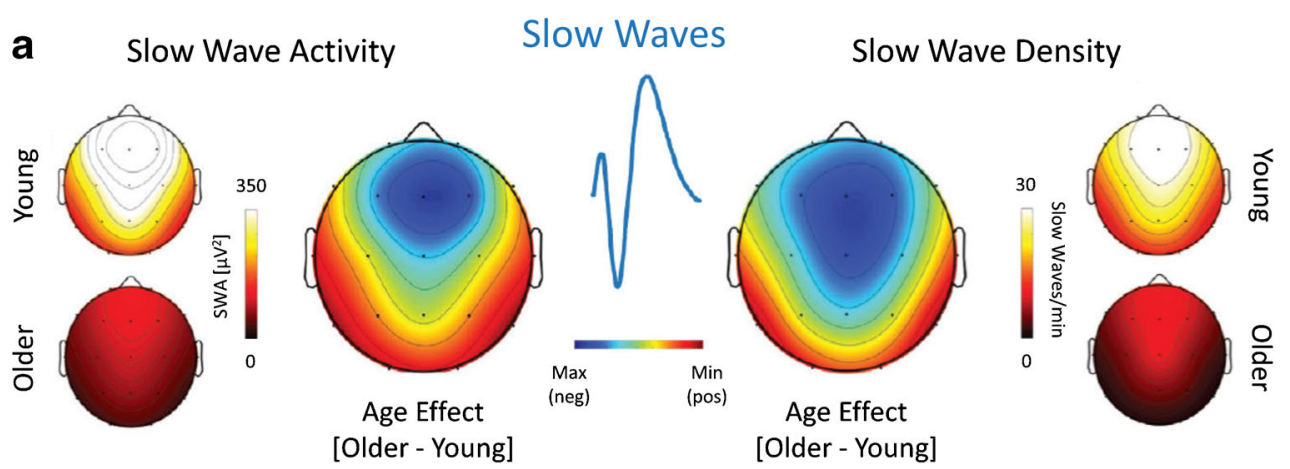

Sleep Spindle

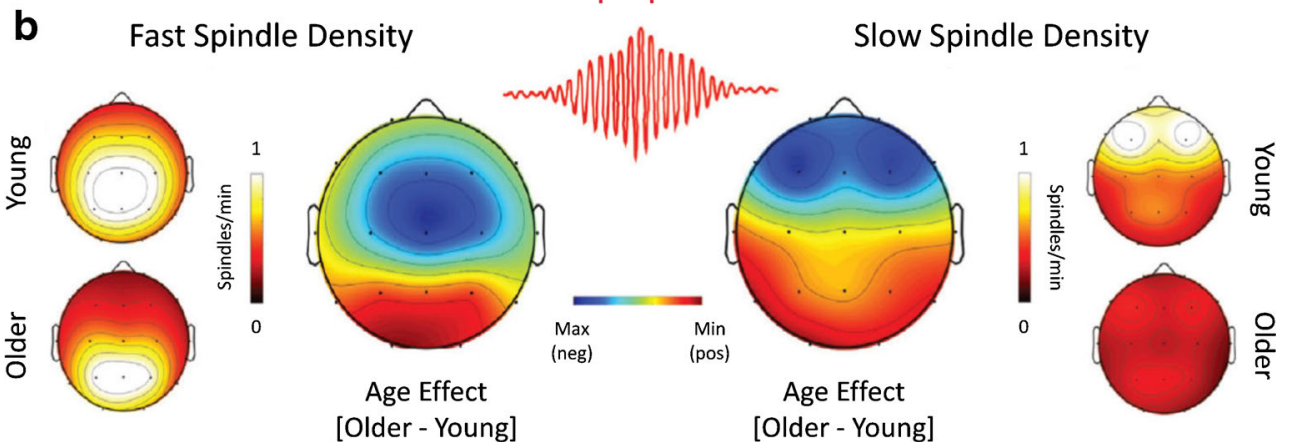

amplitude and density largely decrease with aging [13, 24, 61, cp. Fig. 2]. Decreased SWA and thus glymphatic system function may potentially lead to increased accumulation of toxic brain waste. Notably, several lifestyle factors aside from sleep also influence the glymphatic system [88].

In the course of the night, slow wave slope typically becomes less steep with decreased homeostatic drive [89]. In middle-aged as compared to younger subjects, nocturnal slow wave slopes are decreased, even after controlling for the effect of slow wave amplitude [13]. Absolute theta power was likewise reported to decline with age in nocturnal sleep within the first sleep cycles [36]. Studies imply that slow wave and theta activity share cortical network properties [32, 50].

Whereas N2 duration characteristically increases with age, after reaching a maximum density, duration, and length of sleep, spindles decrease, however with different dynamics. Whereas spindle density declines steadily from adolescence onward to old age, spindle amplitude peaks during childhood and decreases steadily with age. Spindle length peaks already early in life. From young adults to elderly, spindle topography shifts from a wider to a narrower distribution restricted to central sites [16]. In general, the decrement from young to middle-aged adults in spindle power, spindle density and amplitude, slow wave power, amplitude, density, and slope occurs predominantly over frontal/prefrontal regions (Fig. 2) [61, 64, 104]. Impaired spindle features have been speculated to be associated with both reduced white and gray matter and thalamocortical circuit changes (Fig. 2) [16, 61, 62]. In fact, selective atrophy within the medial frontal cortex in older adults predicted a lower degree of SW-spindle coupling of subjects [42].

\section{Chronobiological age and studies in rodents}

Rodents are nocturnal animals and sleep mostly, but not only, during the day in short periods with frequent short awakenings [103, 113, c.p. Fig. 1], thus studies on sleep usually investigate the whole 24-h light-dark phase. In laboratory animals, typically a 12:12 light regime, consisting of 12-h light (inactive) phase and 12-h dark (active) phase, is maintained. The lifespans of mice with about 24 months [45] and of rats with about 3 years [87] are significantly shorter than of humans. Adult mice are mature at an age of 3-6 months, which corresponds to young adults between 20 and 30 years. Mice of 10 14 months are considered middle-aged corresponding to humans between 38 and 47 years and old mice range from 18 to 24 months corresponding to 56-69 years in humans [33]. Adult rats are mature at 6-12 months, middle-aged at about 18 months, and old at an age above 24 months [1]. However, as in human studies, defined age ranges differ between research groups.

Methods utilized for measuring the electrophysiological activity during sleep in laboratory rodents differ from typical human measurements. Human scalp electrodes assess the activity of larger cortical networks as compared to the invasive 
EEG electrodes in rodents. Local field potential recordings reflect activity of even smaller networks [21, 65].

\section{Age-related effects on sleep electrophysiology in mice}

Most investigations on aging were conducted with the C57BL strain $[28,65,72,82,102,103,115,117]$ while a few studies investigated other strains, e.g., DBA/2J [28], the wild type from $\mathrm{Tg} 2576$ [43], or CBA/J [83]. Age-related changes in sleep EEG have been observed (see below), albeit they differ slightly among strains $[28,41]$. Furthermore, almost all studies except for one [43] investigated male mice. Sleep in both sexes was analyzed and compared only once by Sigalas and colleagues [102]. In general, measured sleep parameters across research groups are less consistent than in human research; thus, degree of generalization is lower.

The most consistent result among studies is an increase in NREMS at old ages across a 24-h period [65, 103, 115, 117]. This increment in NREMS corresponds mostly to the augmentation of NREMS during the dark phase [82, 103, 115, 117]. Decreased time spent awake, again especially during the dark phase, appears characteristic of aged mice $[65,82,103,115$, 117]. TST across a $24-\mathrm{h}$ period measured by electrophysiology [65] and by piezoelectric tracking of activity by Paulose et al. [83] also increased with age. Overall, there were no significant changes in REMS time with age in mice (Fig. 3) [65, 103, 117].

Similar to humans, mice present more fragmentation in their sleep during healthy aging. When analyzing sleep and wake bouts (bout refers to the consecutive epochs of a given stage), most studies reported difficulties in wake maintenance and higher sleep pressure that is more evidenced during the dark phase $[72,82,115,117]$. Whereas SWA in the dark phase is often increased in aged mice [65, 82], Wimmer et al. measured a decrease in the relative SWA during the dark phase [117]. An increase in sleep pressure introduced by sleep deprivation, produced in older animals a lower rebound in SWA or a reduced decay rate, suggested to reflect a reduced capacity toward a homeostatic recovery process $[41,65,82]$. To specifically investigate homeostatic features, Panagiotou and colleagues measured slow oscillation/slow wave parameters, and found an increased amplitude and steeper amplitudes underscoring the concept that healthy older mice live under a condition of higher sleep pressure [82]. Theta activity during wakefulness is a correlate of arousal and is reported to positively correlate SWA [112]. Theta peak frequency during REMS in the light phase as well as during wake in the dark phase was slower in older mice suggesting reduced vigilance [117], but no other significant differences were observed for REMS [82, 117].

As detailed by McKillop and colleagues, differences in sleep with aging between humans and mice are associated with their discrepant ecological roles, brain/body size, and metabolism [65]. At a finer scale, not only different strains but substrains of wild-type mice reveal significantly different behavior which may well impact sleep and the expression of aging $[12,35]$. As in humans, sleep EEG in old mice may be modulated by external variables such as exercise [81], diet [79], and light regime [80].

Two of the studies investigating age-related effects on sleep EEG in mice performed their experiments in vitro using brain slices. Sigalas et al. [102] analyzed the barrel cortex in slices with a thickness of $400 \mu \mathrm{m}$ and found a shortened duration of the UP states in the old group, but no differences in
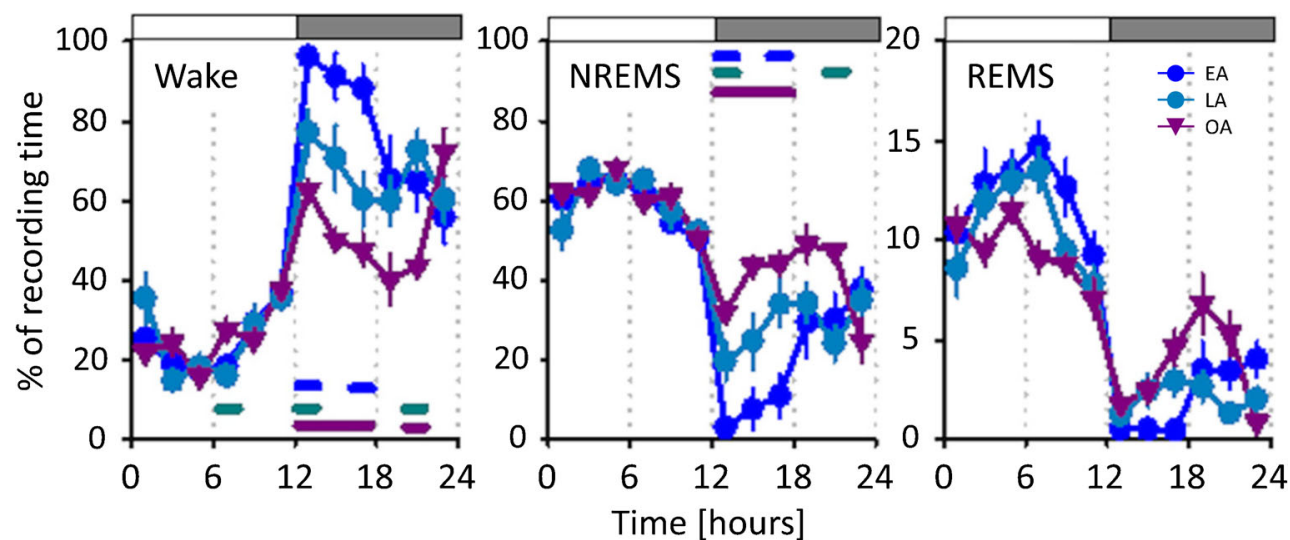

Fig. 3 Age-related differences of sleep states within a sleep-wake cycle of undisturbed sleep in C57BL/6J mice. Diagrams show the time course of wake (left), NREMS (central), and REMS (right) in percentage (mean \pm SEM) across a 24 -h recording period. White and gray top bars indicate the light (inactive) and dark (active) phases, correspondingly. Comparisons are made between early adults (EA, blue), late adulthood (LA, cyan), and old adults (OA, purple) with significant differences comparing EA vs LA (blue), LA vs OA (cyan), and EA vs OA (purple). Data indicate that old mice had a significantly decreased wake and increased NREMS time as compared to younger animals, an effect that is more evident during their active phase. Figure taken and modified with permission from McKillop and colleagues, J Neurosci (2018) 38(16):3911-3928 [65] 
either UP states' density, slow oscillation peak amplitude, peak latency, or in the relative power of the frequencies within the delta to gamma bands. On the other hand, in stratum pyramidale of the CA1 area in hippocampal slices $(450 \mu \mathrm{m}$ thickness), Hermann et al. [43] found a decline in both the sharp wave frequency and the ripple oscillation energy with age that can be explained by a loss in synaptic strength and presynaptic plasticity in the area.

Naidoo and colleagues found a failure of wake orexinergic and noradrenergic neurons in aged mice to increase activity (as measured by c-fos) in response to sleep deprivation, with activity significantly lower than in young mice. This decreased responsiveness of wake active neurons may contribute to wake instability (e.g., shorter duration of wake bouts in the active phase) and dysregulation in the wake/sleep rhythm in aged mice [72]. Orexin (hypocretin) knockout mice, which serve as a model for narcolepsy [14], a sleep disorder in which a loss of orexin has been observed in humans [85, 106], show an increment in sleep intrusion episodes and hypersomnolence during the dark phase. A lower sensitivity to sleep pressure in aging is supported by findings of reduced adenosine $A_{1}$ receptor levels in the hippocampus, cortex, basal ganglia, thalamus, and cerebellum of old mice $[27,78]$.

\section{Age-related effects on sleep electrophysiology in rats}

The effect of healthy aging in the sleep electrophysiology has been investigated in different strains, such as Fisher 344 rats [51, 71, 92, 101, 116], Sprague-Dawley [101, 118], Wistar [17, 110], and Long Evans [57, 96]. All studies were performed in males, except the study by Kostin et al. [51] that used and compared both sexes. Since strain differences in rat sleep have been discovered [91, 101], the age-related effects will be described by strain.

Results on aging in Fisher 344 male rats differ to some extent. Wake time was increased with age within $24 \mathrm{~h}$ [92], although Kostin et al. specified that this effect is observed in quiet wake and not in active wake [51]. NREMS remained unchanged with age during $24-\mathrm{h}$ recordings [92, 101], however was reported to decrease during the light phase and increase during the dark phase in another study [51]. REMS time was decreased with age across $24 \mathrm{~h}$ in the early study [92]; however, recent studies observed a decrease in REMS only during the light phase $[51,101]$. Despite the maintenance of NREMS, Shiromani and colleagues observed a decrease in delta power across $24 \mathrm{~h}$ [101], whereas similar to findings for NREMS, Rosenberg et al. [92] failed to find age-related differences in any frequency band. Similar to humans and mice, in Fisher 344 disturbed sleep-wake regulation with age was reflected by a more fragmented sleep with wake and sleep intrusions $[51,71$,
92]. When sleep macrostructure across the lifespan was analyzed in females, the main difference to males was that aged Fisher 344 females had an increment in REMS during the dark phase [51]. Interactions with external variables were reported for aged F344 rats. For instance, exercise had positive consequences in the sleep EEG from old F344 rats [7]. However, no differences were observed when F344 rats were fed a hypocaloric diet [95].

Recordings of hippocampal ripple activity from the CA1 using tetrodes in male Fisher 344 rats demonstrated that the mean frequency of the ripples $(90-240 \mathrm{~Hz})$ was decreased by age, but not ripple density or duration [116]. Aged Fisher 344 rats reveal reduced extracellular levels of orexin (hypocretin, measured in their cerebrospinal fluid) [22]. In vivo microdialyses measured lower sensitivity of the adenosine $A_{1}$ receptor in the basal forebrain of old Fisher 344 rats [71] reducing the somnogenic activity of adenosine [e.g., 56].

Male Sprague-Dawley rats showed no age-related differences in wake time, TST, NREMS, REMS, and number or duration of sleep and wake bouts or in the EEG spectral power of delta $(0.5-4 \mathrm{~Hz})$, SWA $(2-8 \mathrm{~Hz})$, or theta $(6-9 \mathrm{~Hz})[101$, 118]. These results manifest the strain differences that can be found in the sleep EEG data in aged rats, even using the same experimental conditions.

Two studies investigated effects of aging in male Wistar rats; however, they used different analyses and comparison is difficult $[17,110]$. Clément and colleagues found across $24 \mathrm{~h}$ more sleep fragmentation with age evidenced by a greater number yet shorter REMS episodes, and during the dark phase shorter wake episodes, more wake, NREMS, and REMS episodes [17]. In contrast, Van Gool and Mirmiran [110] found age-related changes during the light phase: more wake and less REMS. Delta $(0.5-4 \mathrm{~Hz})$ absolute power was found to be decreased only in a more recent study [17] while no changes were observed with age in theta power $(4-11 \mathrm{~Hz})[17,110]$. As observed in mice and in Fisher 344 rats, levels of orexin [97] and adenosine $A_{1}$ receptor in the cortex are reduced in aged male Wistar rats as measured by histochemistry and analysis of their gene expression, respectively [15].

Similar to aging humans and mice, the three rat strains discussed above revealed a reduced compensatory increase in SWS or SWA after experimental sleep deprivation [17, $51,101]$ indicating an altered homeostatic process of sleep with age.

Satinoff et al. [96] studied old Long Evans rats from both sexes and found an alteration in the peak neuronal discharge from the SCN, altering the circadian regulation and promoting sleep-wake instability. When studying only old female Long Evans rats, the age-related differences in sleep EEG parameters were observed with a decreased amplitude of the circadian rhythm of body temperature [57]. We are not aware of any further studies specifically targeting sleep in aging Long Evans rats. 


\section{Conclusion}

Effects of aging on brain electric activity in sleep are more consistent in humans than in rodents, revealing a need for more systematic studies on aging in rodents. Although sleep fragmentation is seen by humans and rodents alike, rodents do not reveal the distinguished age-related change in NREMS during the light (inactive) phase. Mice rather reveal increased sleep during the dark (active) phase denoting an increased homeostatic sleep drive, whereas aged humans express a reduced homeostatic sleep need. Yet in humans, systematic investigations on the interaction between homeostatic effects on both napping and nocturnal sleep and circadian process are required. Across species, a deficit in research on female subjects also prevails, a challenge to be overcome. Given the relevance of sleep for basic physiological functions, putative impacts on or interactions with sleep regulation require more intense research. Future research should build on findings underscoring not only system level but also recently disclosed molecular interactions between circadian and homeostatic processes. Translational research must hereby consider essential species-specific differences in regulatory mechanisms.

Acknowledgements Open Access funding enabled and organized by Projekt DEAL. We gratefully thank Prof. Gina R. Poe for providing data, Dr. Ping Chai Koo-Poeggel for helpful discussions, and Sonat Aksamaz and Sonja Binder for technical assistance.

Author contribution DCB and LM wrote the manuscript.

Funding This work was supported by the US-German Collaboration in Computational Neuroscience (NSF/BMBF Grant 01GQ1706) and by the Deutsche Forschungsgemeinschaft [DFG SPP1665 (MA2053/4-2)] to LM.

\section{Declarations}

Conflict of interest The authors declare no competing interests.

Open Access This article is licensed under a Creative Commons Attribution 4.0 International License, which permits use, sharing, adaptation, distribution and reproduction in any medium or format, as long as you give appropriate credit to the original author(s) and the source, provide a link to the Creative Commons licence, and indicate if changes were made. The images or other third party material in this article are included in the article's Creative Commons licence, unless indicated otherwise in a credit line to the material. If material is not included in the article's Creative Commons licence and your intended use is not permitted by statutory regulation or exceeds the permitted use, you will need to obtain permission directly from the copyright holder. To view a copy of this licence, visit http://creativecommons.org/licenses/by/4.0/.

\section{References}

1. Andreollo NA, Santos EF, Araujo MR, Lopes LR (2012) Rat's age versus human's age: what is the relationship? Arq Bras Cir
Dig 25:49-51.https://doi.org/10.1590/s010267202012000100011

2. Barter JD, Foster TC (2018) Aging in the brain: new roles of epigenetics in cognitive decline. Neuroscientist 24:516-525. https://doi.org/10.1177/1073858418780971

3. Benveniste H, Elkin R, Heerdt P, Koundal S, Xue Y, Lee H, Wardlaw J (1985) Tannenbaum A (2020) The glymphatic system and its role in cerebral homeostasis. J Appl Physiol 129:1330 1340. https://doi.org/10.1152/japplphysiol.00852.2019

4. Besedovsky L, Lange T, Haack M (2019) The sleep-immune crosstalk in health and disease. Physiol Rev 99:1325-1380. https://doi.org/10.1152/physrev.00010.2018

5. Besedovsky L, Ngo HV, Dimitrov S, Gassenmaier C, Lehmann R, Born J (2017) Auditory closed-loop stimulation of EEG slow oscillations strengthens sleep and signs of its immune-supportive function. Nat Commun 8:1984. https://doi.org/10.1038/s41467017-02170-3

6. Bjorness TE, Dale N, Mettlach G, Sonneborn A, Sahin B, Fienberg AA, Yanagisawa M, Bibb JA, Greene RW (2016) An adenosine-mediated glial-neuronal circuit for homeostatic sleep. J Neurosci 36:3709-3721. https://doi.org/10.1523/jneurosci.390615.2016

7. Blanco-Centurion CA, Shiromani PJ (2006) Beneficial effects of regular exercise on sleep in old F344 rats. Neurobiol Aging 27: 1859-1869. https://doi.org/10.1016/j.neurobiolaging.2005.10. 009

8. Boivin DB, Shechter A, Boudreau P, Begum EA, Ng Ying-Kin NM (2016) Diurnal and circadian variation of sleep and alertness in men vs. naturally cycling women. Proc Natl Acad Sci U S A 113:10980-10985. https://doi.org/10.1073/pnas.1524484113

9. Borbély AA, Daan S, Wirz-Justice A, Deboer T (2016) The twoprocess model of sleep regulation: a reappraisal. J Sleep Res 25: 131-143. https://doi.org/10.1111/jsr.12371

10. Cajochen C, Münch M, Knoblauch V, Blatter K, Wirz-Justice A (2006) Age-related changes in the circadian and homeostatic regulation of human sleep. Chronobiol Int 23:461-474. https://doi. org/10.1080/07420520500545813

11. Campino C, Valenzuela FJ, Torres-Farfan C, Reynolds HE, Abarzua-Catalan L, Arteaga E, Trucco C, Guzmán S, Valenzuela GJ, Seron-Ferre M (2011) Melatonin exerts direct inhibitory actions on ACTH responses in the human adrenal gland. Horm Metab Res 43:337-342. https://doi.org/10.1055/s0031-1271693

12. Capri KM, Maroni MJ, Deane HV, Concepcion HA, DeCourcey H, Logan RW, Seggio JA (2019) Male C57BL6/N and C57BL6/J mice respond differently to constant light and running-wheel access. Front Behav Neurosci 13:268. https://doi.org/10.3389/fnbeh. 2019.00268

13. Carrier J, Viens I, Poirier G, Robillard R, Lafortune M, Vandewalle G, Martin N, Barakat M, Paquet J, Filipini D (2011) Sleep slow wave changes during the middle years of life. Eur J Neurosci 33:758-766. https://doi.org/10.1111/j.1460-9568. 2010.07543.x

14. Chemelli RM, Willie JT, Sinton CM, Elmquist JK, Scammell T, Lee C, Richardson JA, Williams SC, Xiong Y, Kisanuki Y, Fitch TE, Nakazato M, Hammer RE, Saper CB, Yanagisawa M (1999) Narcolepsy in orexin knockout mice: molecular genetics of sleep regulation. Cell 98:437-451. https://doi.org/10.1016/s00928674(00)81973-x

15. Cheng JT, Liu IM, Juang SW, Jou SB (2000) Decrease of adenosine A-1 receptor gene expression in cerebral cortex of aged rats. Neurosci Lett 283:227-229

16. Clawson BC, Durkin J, Aton SJ (2016) Form and function of sleep spindles across the lifespan. Neural Plast 2016:69363816936316. https://doi.org/10.1155/2016/6936381 
17. Clément P, Gharib A, Cespuglio R, Sarda N (2003) Changes in the sleep-wake cycle architecture and cortical nitric oxide release during ageing in the rat. Neuroscience 116:863-870

18. Coria-Lucero CD, Golini RS, Ponce IT, Deyurka N, Anzulovich AC, Delgado SM, Navigatore-Fonzo LS (2016) Rhythmic Bdnf and TrkB expression patterns in the prefrontal cortex are lost in aged rats. Brain Res 1653:51-58. https://doi.org/10.1016/j. brainres.2016.10.019

19. Curie T, Maret S, Emmenegger Y, Franken P (2015) In vivo imaging of the central and peripheral effects of sleep deprivation and suprachiasmatic nuclei lesion on PERIOD-2 protein in mice. Sleep 38:1381-1394. https://doi.org/10.5665/sleep.4974

20. Daneault V, Dumont M, Massé É, Vandewalle G, Carrier J (2016) Light-sensitive brain pathways and aging. J Physiol Anthropol 35: 9. https://doi.org/10.1186/s40101-016-0091-9

21. del Campo CM, Velázquez JL, Freire MA (2009) EEG recording in rodents, with a focus on epilepsy. Curr Protoc Neurosci Chapter 6:Unit 6.24. https://doi.org/10.1002/0471142301. ns0624s 49

22. Desarnaud F, Murillo-Rodriguez E, Lin L, Xu M, Gerashchenko D, Shiromani SN, Nishino S, Mignot E, Shiromani PJ (2004) The diurnal rhythm of hypocretin in young and old F344 rats. Sleep 27: 851-856. https://doi.org/10.1093/sleep/27.5.851

23. Dewandre D, Atienza M, Sanchez-Espinosa MP, Cantero JL (2018) Effects of PER3 clock gene polymorphisms on agingrelated changes of the cerebral cortex. Brain Struct Funct 223: 597-607. https://doi.org/10.1007/s00429-017-1513-0

24. Dubé J, Lafortune M, Bedetti C, Bouchard M, Gagnon JF, Doyon J, Evans AC, Lina JM, Carrier J (2015) Cortical thinning explains changes in sleep slow waves during adulthood. J Neurosci 35: 7795-7807. https://doi.org/10.1523/jneurosci.3956-14.2015

25. Duffy JF, Zitting KM, Chinoy ED (2015) Aging and circadian rhythms. Sleep Med Clin 10:423-434. https://doi.org/10.1016/j. jsmc.2015.08.002

26. Edwards BA, O'Driscoll DM, Ali A, Jordan AS, Trinder J, Malhotra A (2010) Aging and sleep: physiology and pathophysiology. Semin Respir Crit Care Med 31:618-633. https://doi.org/ 10.1055/s-0030-1265902

27. Ekonomou A, Sperk G, Kostopoulos G, Angelatou F (2000) Reduction of A1 adenosine receptors in rat hippocampus after kainic acid-induced limbic seizures. Neurosci Lett 284:49-52. https://doi.org/10.1016/s0304-3940(00)00954-x

28. Eleftheriou BE, Zolovick AJ, Elias MF (1975) Electroencephalographic changes with age in male mice. Gerontologia 21:21-30. https://doi.org/10.1159/000212027

29. Erickson MA, Banks WA (2019) Age-associated changes in the immune system and blood brain barrier functions. Int J Mol Sci: 20. https://doi.org/10.3390/ijms20071632

30. Faraut B, Andrillon T, Vecchierini MF, Leger D (2017) Napping: a public health issue. From epidemiological to laboratory studies. Sleep Med Rev 35:85-100. https://doi.org/10.1016/j.smrv.2016. 09.002

31. Fifel K, Meijer JH, Deboer T (2018) Circadian and homeostatic modulation of multi-unit activity in midbrain dopaminergic structures. Sci Rep 8:7765. https://doi.org/10.1038/s41598-018-257705

32. Finelli LA, Baumann H, Borbély AA, Achermann P (2000) Dual electroencephalogram markers of human sleep homeostasis: correlation between theta activity in waking and slow-wave activity in sleep. Neuroscience 101:523-529. https://doi.org/10.1016/ s0306-4522(00)00409-7

33. Flurkey K, Currer JM, Harrison DE (2007) Mouse models in aging research. In: Fox JG et al (eds) The mouse in biomedical research, vol III, 2nd edn. American College Laboratory Animal Medicine (Elsevier), Burlington, pp 637-672. https://doi.org/10. 1016/B978-012369454-6/50074-1
34. Franken P, Dijk DJ (2009) Circadian clock genes and sleep homeostasis. Eur J Neurosci 29:1820-1829. https://doi.org/10.1111/ j.1460-9568.2009.06723.x

35. Franken P, Malafosse A, Tafti M (1999) Genetic determinants of sleep regulation in inbred mice. Sleep 22:155-169

36. Gaudreau H, Carrier J, Tchiteya BM (2005) Age and individual determinants of sleep loss effects. In: Kushida CA (ed) Sleep deprivation, basic science, physiology, and behavior, vol, vol 192. Marcel Dekker, New York, pp 441-479

37. Gautier-Sauvigné S, Colas D, Parmantier P, Clement P, Gharib A, Sarda N, Cespuglio R (2005) Nitric oxide and sleep. Sleep Med Rev 9:101-113. https://doi.org/10.1016/j.smrv.2004.07.004

38. Gazerani P (2020) Epigenetics of sleep disruption. OBM Neurobiol:4-25. https://doi.org/10.21926/obm.neurobiol. 2003071

39. Guo X, Keenan BT, Sarantopoulou D, Lim DC, Lian J, Grant GR, Pack AI (2019) Age attenuates the transcriptional changes that occur with sleep in the medial prefrontal cortex. Aging Cell 18: e13021. https://doi.org/10.1111/acel.13021

40. Gupta D, Morley JE (2014) Hypothalamic-pituitary-adrenal (HPA) axis and aging. Compr Physiol 4:1495-1510. https://doi. org/10.1002/cphy.c130049

41. Hasan S, Dauvilliers Y, Mongrain V, Franken P, Tafti M (2012) Age-related changes in sleep in inbred mice are genotype dependent. Neurobiol Aging 33(195):e113-e126. https://doi.org/10. 1016/j.neurobiolaging.2010.05.010

42. Helfrich RF, Mander BA, Jagust WJ, Knight RT, Walker MP (2018) Old brains come uncoupled in sleep: slow wave-spindle synchrony, brain atrophy, and forgetting. Neuron 97:221230.e224. https://doi.org/10.1016/j.neuron.2017.11.020

43. Hermann D, Both M, Ebert U, Gross G, Schoemaker H, Draguhn A, Wicke K, Nimmrich V (2009) Synaptic transmission is impaired prior to plaque formation in amyloid precursor proteinoverexpressing mice without altering behaviorally-correlated sharp wave-ripple complexes. Neuroscience 162:1081-1090. https://doi.org/10.1016/j.neuroscience.2009.05.044

44. Hung CS, Sarasso S, Ferrarelli F, Riedner B, Ghilardi MF, Cirelli C, Tononi G (2013) Local experience-dependent changes in the wake EEG after prolonged wakefulness. Sleep 36:59-72. https:// doi.org/10.5665/sleep.2302

45. Ingram DK, London ED, Reynolds MA (1982) Circadian rhythmicity and sleep: effects of aging in laboratory animals. Neurobiol Aging 3:287-297. https://doi.org/10.1016/0197-4580(82)900173

46. Jones BE (2017) Principal cell types of sleep-wake regulatory circuits. Curr Opin Neurobiol 44:101-109. https://doi.org/10. 1016/j.conb.2017.03.018

47. Jones BE (2020) Arousal and sleep circuits. Neuropsychopharmacology 45:6-20. https://doi.org/10.1038/ s41386-019-0444-2

48. Kelmer Sacramento E, Kirkpatrick JM, Mazzetto M, Baumgart M, Bartolome A, Di Sanzo S, Caterino C, Sanguanini M, Papaevgeniou N, Lefaki M, Childs D, Bagnoli S, Terzibasi Tozzini E, Di Fraia D, Romanov N, Sudmant PH, Huber W, Chondrogianni N, Vendruscolo M, Cellerino A, Ori A (2020) Reduced proteasome activity in the aging brain results in ribosome stoichiometry loss and aggregation. Mol Syst Biol 16:e9596. https://doi.org/10.15252/msb.20209596

49. Kim K, Choe HK (2019) Role of hypothalamus in aging and its underlying cellular mechanisms. Mech Ageing Dev 177:74-79. https://doi.org/10.1016/j.mad.2018.04.008

50. Kirov R, Weiss C, Siebner HR, Born J, Marshall L (2009) Slow oscillation electrical brain stimulation during waking promotes EEG theta activity and memory encoding. Proc Natl Acad Sci U S A 106:15460-15465. https://doi.org/10.1073/pnas.0904438106 
51. Kostin A, Alam MA, Siegel JM, McGinty D, Alam MN (2020) Sex- and age-dependent differences in sleep-wake characteristics of Fisher-344 Rats. Neuroscience 427:29-42. https://doi.org/10. 1016/j.neuroscience.2019.11.046

52. Krueger JM (2020) Sleep and circadian rhythms: evolutionary entanglement and local regulation. Neurobiol Sleep Circadian Rhythms 9:100052. https://doi.org/10.1016/j.nbscr.2020.100052

53. Krueger JM, Frank MG, Wisor JP, Roy S (2016) Sleep function: toward elucidating an enigma. Sleep Med Rev 28:46-54. https:// doi.org/10.1016/j.smrv.2015.08.005

54. Lananna BV, Musiek ES (2020) The wrinkling of time: aging, inflammation, oxidative stress, and the circadian clock in neurodegeneration. Neurobiol Dis 139:104832. https://doi.org/10.1016/ j.nbd.2020.104832

55. Landolt HP, Borbély AA (2001) Age-dependent changes in sleep EEG topography. Clin Neurophysiol 112:369-377. https://doi. org/10.1016/s1388-2457(00)00542-3

56. Lazarus M, Chen JF, Huang ZL, Urade Y, Fredholm BB (2019) Adenosine and sleep. Handb Exp Pharmacol 253:359-381. https://doi.org/10.1007/164_2017_36

57. Li H, Satinoff E (1995) Changes in circadian rhythms of body temperature and sleep in old rats. Am J Physiol 269:R208R214. https://doi.org/10.1152/ajpregu.1995.269.1.R208

58. Li J, Vitiello MV, Gooneratne NS (2018) Sleep in normal aging. Sleep Med Clin 13:1-11. https://doi.org/10.1016/j.jsmc.2017.09.001

59. Liu KY, Acosta-Cabronero J, Cardenas-Blanco A, Loane C, Berry AJ, Betts MJ, Kievit RA, Henson RN, Düzel E, Howard R, Hämmerer D (2019) In vivo visualization of age-related differences in the locus coeruleus. Neurobiol Aging 74:101-111. https://doi.org/10.1016/j.neurobiolaging.2018.10.014

60. Mander BA, Rao V, Lu B, Saletin JM, Ancoli-Israel S, Jagust WJ, Walker MP (2014) Impaired prefrontal sleep spindle regulation of hippocampal-dependent learning in older adults. Cereb Cortex 24: 3301-3309. https://doi.org/10.1093/cercor/bht188

61. Mander BA, Winer JR, Walker MP (2017) Sleep and human aging. Neuron 94:19-36. https://doi.org/10.1016/j.neuron.2017.02.004

62. Mander BA, Zhu AH, Lindquist JR, Villeneuve S, Rao V, Lu B, Saletin JM, Ancoli-Israel S, Jagust WJ, Walker MP (2017) White matter structure in older adults moderates the benefit of sleep spindles on motor memory consolidation. J Neurosci 37:1167511687. https://doi.org/10.1523/jneurosci.3033-16.2017

63. Marshall L, Cross N, Binder S, Dang-Vu TT (2020) Brain rhythms during sleep and memory consolidation: neurobiological insights. Physiology (Bethesda) 35:4-15. https://doi.org/10.1152/ physiol.00004.2019

64. Martin N, Lafortune M, Godbout J, Barakat M, Robillard R, Poirier G, Bastien C, Carrier J (2013) Topography of age-related changes in sleep spindles. Neurobiol Aging 34:468-476. https:// doi.org/10.1016/j.neurobiolaging.2012.05.020

65. McKillop LE, Fisher SP, Cui N, Peirson SN, Foster RG, Wafford KA, Vyazovskiy VV (2018) Effects of aging on cortical neural dynamics and local sleep homeostasis in mice. J Neurosci 38: 3911-3928. https://doi.org/10.1523/jneurosci.2513-17.2018

66. Mieda M, Hasegawa E, Kessaris N, Sakurai T (2017) Fine-tuning circadian rhythms: the importance of bmall expression in the ventral forebrain. Front Neurosci 11:55. https://doi.org/10.3389/fnins. 2017.00055

67. Milner CE, Cote KA (2009) Benefits of napping in healthy adults: impact of nap length, time of day, age, and experience with napping. J Sleep Res 18:272-281. https://doi.org/10.1111/j.13652869.2008.00718.x

68. Mishina M, Kimura Y, Sakata M, Ishii K, Oda K, Toyohara J, Kimura K, Ishiwata K (2017) Age-related decrease in male extrastriatal adenosine $\mathrm{A}(1)$ receptors measured using(11)C-MPDX PET. Front Pharmacol 8:903. https://doi.org/10.3389/fphar.2017. 00903
69. Mourrain P, Wang GX (2019) Sleep: DNA repair function for better neuronal aging? Curr Biol 29:R585-r588. https://doi.org/ 10.1016/j.cub.2019.05.018

70. Münch M, Knoblauch V, Blatter K, Schröder C, Schnitzler C, Kräuchi K, Wirz-Justice A, Cajochen C (2004) The frontal predominance in human EEG delta activity after sleep loss decreases with age. Eur J Neurosci 20:1402-1410. https://doi.org/10.1111/j. 1460-9568.2004.03580.x

71. Murillo-Rodriguez E, Blanco-Centurion C, Gerashchenko D, Salin-Pascual RJ, Shiromani PJ (2004) The diurnal rhythm of adenosine levels in the basal forebrain of young and old rats. Neuroscience 123:361-370. https://doi.org/10.1016/j. neuroscience.2003.09.015

72. Naidoo N, Zhu J, Zhu Y, Fenik P, Lian J, Galante R, Veasey S (2011) Endoplasmic reticulum stress in wake-active neurons progresses with aging. Aging Cell 10:640-649. https://doi.org/10. 1111/j.1474-9726.2011.00699.x

73. Nakamura TJ, Nakamura W, Tokuda IT, Ishikawa T, Kudo T, Colwell CS, Block GD (2015) Age-related changes in the circadian system unmasked by constant conditions. eNeuro:2ENEU15.2015. https://doi.org/10.1523/eneuro.0064-15.2015

74. Nelson AB, Ricci S, Tatti E, Panday P, Girau E, Lin J, Thomson BO, Chen H, Marshall W, Tononi G, Cirelli C, Ghilardi MF (2020) Neural fatigue due to intensive learning is reversed by a nap but not by quiet waking. Sleep 44. https://doi.org/10.1093/ sleep/zsaa143

75. Noya SB, Colameo D, Brüning F, Spinnler A, Mircsof D, Opitz L, Mann M, Tyagarajan SK, Robles MS, Brown SA (2019) The forebrain synaptic transcriptome is organized by clocks but its proteome is driven by sleep. Science:366. https://doi.org/10. 1126/science.aav2642

76. Ohayon MM, Carskadon MA, Guilleminault C, Vitiello MV (2004) Meta-analysis of quantitative sleep parameters from childhood to old age in healthy individuals: developing normative sleep values across the human lifespan. Sleep 27:1255-1273. https:// doi.org/10.1093/sleep/27.7.1255

77. Pace-Schott EF, Spencer RM (2011) Age-related changes in the cognitive function of sleep. Prog Brain Res 191:75-89. https://doi. org/10.1016/b978-0-444-53752-2.00012-6

78. Pagonopoulou O, Angelatou F (1992) Reduction of A1 adenosine receptors in cortex, hippocampus and cerebellum in ageing mouse brain. Neuroreport 3:735-737. https://doi.org/10.1097/00001756199209000-00003

79. Panagiotou M, Deboer T (2019) Chronic high-caloric diet accentuates age-induced sleep alterations in mice. Behav Brain Res 362: 131-139. https://doi.org/10.1016/j.bbr.2019.01.017

80. Panagiotou M, Deboer T (2020) Effects of chronic dim-light-atnight exposure on sleep in young and aged mice. Neuroscience 426:154-167. https://doi.org/10.1016/j.neuroscience.2019.11.033

81. Panagiotou M, Papagiannopoulos K, Rohling JHT, Meijer JH, Deboer T (2018) How old is your brain? Slow-wave activity in non-rapid-eye-movement sleep as a marker of brain rejuvenation after long-term exercise in mice. Front Aging Neurosci 10:233. https://doi.org/10.3389/fnagi.2018.00233

82. Panagiotou M, Vyazovskiy VV, Meijer JH, Deboer T (2017) Differences in electroencephalographic non-rapid-eye movement sleep slow-wave characteristics between young and old mice. Sci Rep 7:43656. https://doi.org/10.1038/srep43656

83. Paulose JK, Wang C, O'Hara BF, Cassone VM (2019) The effects of aging on sleep parameters in a healthy, melatonin-competent mouse model. Nat Sci Sleep 11:113-121. https://doi.org/10.2147/ NSS.S214423

84. Peng W, Wu Z, Song K, Zhang S, Li Y, Xu M (2020) Regulation of sleep homeostasis mediator adenosine by basal forebrain glutamatergic neurons. Science 369:eabb0556. https://doi.org/10.1126/ science.abb0556 
85. Peyron C, Faraco J, Rogers W, Ripley B, Overeem S, Charnay Y, Nevsimalova S, Aldrich M, Reynolds D, Albin R, Li R, Hungs M, Pedrazzoli M, Padigaru M, Kucherlapati M, Fan J, Maki R, Lammers GJ, Bouras C, Kucherlapati R, Nishino S, Mignot E (2000) A mutation in a case of early onset narcolepsy and a generalized absence of hypocretin peptides in human narcoleptic brains. Nat Med 6:991-997. https://doi.org/10.1038/79690

86. Poe GR, Foote S, Eschenko O, Johansen JP, Bouret S, AstonJones G, Harley CW, Manahan-Vaughan D, Weinshenker D, Valentino R, Berridge C, Chandler DJ, Waterhouse B, Sara SJ (2020) Locus coeruleus: a new look at the blue spot. Nat Rev Neurosci 21:644-659. https://doi.org/10.1038/s41583-020-03609

87. Quinn R (2005) Comparing rat's to human's age: how old is my rat in people years? Nutrition 21:775-777. https://doi.org/10. 1016/j.nut.2005.04.002

88. Reddy OC, van der Werf YD (2020) The sleeping brain: harnessing the power of the glymphatic system through lifestyle choices. Brain Sci 10. https://doi.org/10.3390/brainsci10110868

89. Riedner BA, Vyazovskiy VV, Huber R, Massimini M, Esser S, Murphy M, Tononi G (2007) Sleep homeostasis and cortical synchronization: III A high-density EEG study of sleep slow waves in humans. Sleep 30:1643-1657. https://doi.org/10.1093/sleep/30. 12.1643

90. Rolls A (2012) Hypothalamic control of sleep in aging. Neuromolecular Med 14:139-153. https://doi.org/10.1007/ s12017-012-8175-0

91. Rosenberg RS, Bergmann BM, Son HJ, Arnason BG, Rechtschaffen A (1987) Strain differences in the sleep of rats. Sleep 10:537-541

92. Rosenberg RS, Zepelin H, Rechtschaffen A (1979) Sleep in young and old rats. J Gerontol 34:525-532

93. Rosinvil T, Lafortune M, Sekerovic Z, Bouchard M, Dubé J, Latulipe-Loiselle A, Martin N, Lina JM, Carrier J (2015) Agerelated changes in sleep spindles characteristics during daytime recovery following a 25-hour sleep deprivation. Front Hum Neurosci 9:323. https://doi.org/10.3389/fnhum.2015.00323

94. Rozycka A, Charzynska A, Misiewicz Z, Maciej Stepniewski T, Sobolewska A, Kossut M, Liguz-Lecznar M (2019) Glutamate, GABA, and presynaptic markers involved in neurotransmission are differently affected by age in distinct mouse brain regions. ACS Chem Neurosci 10:4449-4461. https://doi.org/10.1021/ acschemneuro.9b00220

95. Salin-Pascual RJ, Upadhyay U, Shiromani PJ (2002) Effects of hypocaloric diet on sleep in young and old rats. Neurobiol Aging 23:771-776. https://doi.org/10.1016/s0197-4580(02)00030-1

96. Satinoff E, Li H, Tcheng TK, Liu C, McArthur AJ, Medanic M, Gillette MU (1993) Do the suprachiasmatic nuclei oscillate in old rats as they do in young ones? Am J Physiol 265:R1216-R1222. https://doi.org/10.1152/ajpregu.1993.265.5.R1216

97. Sawai N, Ueta Y, Nakazato M, Ozawa H (2010) Developmental and aging change of orexin-A and -B immunoreactive neurons in the male rat hypothalamus. Neurosci Lett 468:51-55. https://doi. org/10.1016/j.neulet.2009.10.061

98. Scheiblich H, Trombly M, Ramirez A, Heneka MT (2020) Neuroimmune connections in aging and neurodegenerative diseases. Trends Immunol 41:300-312. https://doi.org/10.1016/j.it. 2020.02.002

99. Schmid SM, Hallschmid M, Schultes B (2015) The metabolic burden of sleep loss. Lancet Diabetes Endocrinol 3:52-62. https://doi.org/10.1016/s2213-8587(14)70012-9

100. Scullin MK, Bliwise DL (2015) Sleep, cognition, and normal aging: integrating a half century of multidisciplinary research. Perspect Psychol Sci 10:97-137. https://doi.org/10.1177/ 1745691614556680
101. Shiromani PJ, Lu J, Wagner D, Thakkar J, Greco MA, Basheer R, Thakkar M (2000) Compensatory sleep response to $12 \mathrm{~h}$ wakefulness in young and old rats. Am J Physiol Regul Integr Comp Physiol 278:R125-R133. https://doi.org/10.1152/ajpregu.2000. 278.1.R125

102. Sigalas C, Konsolaki E, Skaliora I (2017) Sex differences in endogenous cortical network activity: spontaneously recurring up/ down states. Biol Sex Differ 8:21. https://doi.org/10.1186/s13293017-0143-9

103. Soltani S, Chauvette S, Bukhtiyarova O, Lina JM, Dube J, Seigneur J, Carrier J, Timofeev I (2019) Sleep-wake cycle in young and older mice. Front Syst Neurosci 13:51. https://doi. org $/ 10.3389 /$ fnsys.2019.00051

104. Sprecher KE, Riedner BA, Smith RF, Tononi G, Davidson RJ, Benca RM (2016) High resolution topography of age-related changes in non-rapid eye movement sleep electroencephalography. PLoS One 11:e0149770. https://doi.org/10.1371/journal. pone. 0149770

105. Steiger A (2003) Sleep and endocrinology. J Intern Med 254:1322. https://doi.org/10.1046/j.1365-2796.2003.01175.x

106. Thannickal TC, Moore RY, Nienhuis R, Ramanathan L, Gulyani S, Aldrich M, Cornford M, Siegel JM (2000) Reduced number of hypocretin neurons in human narcolepsy. Neuron 27:469-474. https://doi.org/10.1016/s0896-6273(00)00058-1

107. Tononi G, Cirelli C (2014) Sleep and the price of plasticity: from synaptic and cellular homeostasis to memory consolidation and integration. Neuron 81:12-34. https://doi.org/10.1016/j.neuron. 2013.12.025

108. Van Cauter E, Plat L, Leproult R, Copinschi G (1998) Alterations of circadian rhythmicity and sleep in aging: endocrine consequences. Horm Res 49:147-152. https://doi.org/10.1159/ 000023162

109. van Coevorden A, Mockel J, Laurent E, Kerkhofs M, L'HermiteBalériaux M, Decoster C, Nève P, Van Cauter E (1991) Neuroendocrine rhythms and sleep in aging men. Am J Physiol 260:E651-E661. https://doi.org/10.1152/ajpendo.1991.260.4. E651

110. Van Gool WA, Mirmiran M (1983) Age-related changes in the sleep pattern of male adult rats. Brain Res 279:394-398

111. Van Someren EJ, Raymann RJ, Scherder EJ, Daanen HA, Swaab DF (2002) Circadian and age-related modulation of thermoreception and temperature regulation: mechanisms and functional implications. Ageing Res Rev 1:721-778. https://doi. org/10.1016/s1568-1637(02)00030-2

112. Vyazovskiy VV, Tobler I (2005) Theta activity in the waking EEG is a marker of sleep propensity in the rat. Brain Res 1050:64-71. https://doi.org/10.1016/j.brainres.2005.05.022

113. Watson BO, Levenstein D, Greene JP, Gelinas JN, Buzsáki G (2016) Network homeostasis and state dynamics of neocortical sleep. Neuron 90:839-852. https://doi.org/10.1016/j.neuron. 2016.03.036

114. Weinert D (2000) Age-dependent changes of the circadian system. Chronobiol Int 17:261-283. https://doi.org/10.1081/cbi100101048

115. Welsh DK, Richardson GS, Dement WC (1986) Effect of age on the circadian pattern of sleep and wakefulness in the mouse. $\mathrm{J}$ Gerontol 41:579-586

116. Wiegand JP, Gray DT, Schimanski LA, Lipa P, Barnes CA, Cowen SL (2016) Age is associated with reduced sharp-wave ripple frequency and altered patterns of neuronal variability. $\mathrm{J}$ Neurosci 36:5650-5660. https://doi.org/10.1523/JNEUROSCI. 3069-15.2016

117. Wimmer ME, Rising J, Galante RJ, Wyner A, Pack AI, Abel T (2013) Aging in mice reduces the ability to sustain sleep/wake states. PLoS One 8:e81880. https://doi.org/10.1371/journal.pone. 0081880 
118. Zepelin H, Whitehead WE, Rechtschaffen A (1972) Aging and sleep in the albino rat. Behav Biol 7:65-74

119. Zhao J, Warman GR, Cheeseman JF (2019) The functional changes of the circadian system organization in aging. Ageing Res Rev 52:64-71. https://doi.org/10.1016/j.arr.2019.04.006

120. Zhong HH, Yu B, Luo D, Yang LY, Zhang J, Jiang SS, Hu SJ, Luo YY, Yang MW, Hong FF, Yang SL (2019) Roles of aging in sleep. Neurosci Biobehav Rev 98:177-184. https://doi.org/10. 1016/j.neubiorev.2019.01.013
121. Zhou JN, Liu RY, van Heerikhuize J, Hofman MA, Swaab DF (2003) Alterations in the circadian rhythm of salivary melatonin begin during middle-age. J Pineal Res 34:11-16. https://doi.org/ 10.1034/j.1600-079x.2003.01897.x

Publisher's note Springer Nature remains neutral with regard to jurisdictional claims in published maps and institutional affiliations. 